\title{
Globin's Structure and Function in Vesicomyid Bivalves from the Gulf of Guinea Cold Seeps as an Adaptation to Life in Reduced Sediments
}

\author{
C. Decker ${ }^{1,2,3}$ \\ N. Zorn ${ }^{4}$ \\ N. Potier ${ }^{4}$ \\ E. Leize-Wagner ${ }^{4}$ \\ F. H. Lallier ${ }^{2,3}$ \\ K. Olu ${ }^{1}$ \\ A. C. Andersen ${ }^{2,3, *}$ \\ ${ }^{1}$ IFREMER, Laboratoire Environnement Profond, Unité de \\ Recherche Etude des Ecosystèmes Profonds, F-29280 \\ Plouzané, France; ${ }^{2}$ Sorbonne Universités, Université Pierre \\ et Marie Curie Université Paris 06, Unité Mixte de Recherche \\ (UMR) 7144, Équipe Adaptation et Biologie des Invertébrés \\ en Conditions Extrêmes, Station Biologique, F-29680 Roscoff, \\ France; ${ }^{3}$ Centre National de la Recherche Scientifique \\ (CNRS), UMR 7144, Adaptation et Diversité en Milieu Marin, \\ Station Biologique, F-29680 Roscoff, France; ${ }^{4}$ Laboratoire de \\ Spectrométrie de Masse des Interactions et des Systèmes, \\ UMR 7140, CNRS-Université Louis Pasteur Chimie de la \\ Matière Complexe, F-67008 Strasbourg, France
}

Accepted 7/11/2014; Electronically Published 10/29/2014

Online enhancement: supplementary table.

\begin{abstract}
Vesicomyid bivalves form dense clam beds in both deepsea cold seeps and hydrothermal vents. The species diversity within this family raises questions about niche separation and specific adaptations. To compare their abilities to withstand hypoxia, we have studied the structure and function of erythrocyte hemoglobin $(\mathrm{Hb})$ and foot myoglobin $(\mathrm{Mb})$ from two vesicomyid species, Christineconcha regab and Laubiericoncha chuni, collected from the Regab pockmark in the Gulf of Guinea at a depth of 3,000 m. Laubiericoncha chuni possesses three monomeric globins, G1 (15,361 Da), G2 (15,668 $\mathrm{Da})$, and $\mathrm{G} 3(15,682 \mathrm{Da})$ in circulating erythrocytes $(\mathrm{Hb})$, and also three globins, G1, G3, and G4 (14,786 Da) in foot muscle $(\mathrm{Mb})$. Therefore, globins G2 and G4 appear to be specific for erythrocytes and muscle, respectively, but globins G1 and G3 are common. In contrast, $C$. regab lacks erythrocyte $\mathrm{Hb}$ completely and possesses only globin monomers G1' (14,941 Da),
\end{abstract}

*Corresponding author; e-mail: andersen@sb-roscoff.fr.

Physiological and Biochemical Zoology 87(6):855-869. 2014. (c) 2014 by The University of Chicago. All rights reserved. 1522-2152/2014/8706-3160\$15.00. DOI: $10.1086 / 678131$
G2' (15,169 Da), and G3' (15,683 Da) in foot muscle. Thus, these two vesicomyid species, C. regab and L. chuni, show a remarkable diversity in globin expression when examined by electrospray ionization mass spectrometry. Oxygen-binding affinities reveal extremely high oxygen affinities $\left(\mathrm{P}_{50}<1\right.$ Torr, from $5^{\circ}$ to $15^{\circ} \mathrm{C}$ at $\mathrm{pH} 7.5$ ), in particular L. chuni globins, which might be an advantage allowing $L$. chuni to dig deeply for sulfides and remain buried for long periods in reduced sediments.

\section{Introduction}

Vesicomyid clams are heterodont bivalve mollusks that live worldwide on the deep-sea floor from 100 to 9,500 m depth (Krylova and Sahling 2010). Most of the 120 vesicomyid species described to date are found in reducing environments on the continental margins or along oceanic ridges (Krylova and Sahling 2010). They also form dense patches around seepages at hydrothermal vents, cold seeps, and whale falls (Sibuet and Olu 1998). Some species have been found at a single site only, raising questions about niche separation and specific adaptations, but very few studies have been dedicated so far to clam physiology (Barry and Kochevar 1998; Goffredi and Barry 2002). Vesicomyids have only rudimentary guts and rely instead on thioautotrophic gill endosymbionts for nutrition (Cavanaugh 1983; Fiala-Médioni and Le Pennec 1987). The bivalve host fuels its symbionts with sulfides taken up by its foot that can extend in the sediment (or in basaltic crevices at vents), while oxygen and carbon dioxide from the seawater above enters through the vertical siphons (Arp et al. 1984). Most vesicomyids live in sulfide-rich sediment, but concentrations may be quite variable (Hashimoto et al. 1989; Sahling et al. 2002; Levin et al. 2003). For example, at seeps in Monterey Bay, Phreagena kilmeri dominates in areas with sulfide levels between 4 and $18 \mathrm{mM}$, whereas Calyptogena pacifica prefers lower sulfide concentrations (0-4 mM; Barry et al. 1997).

Whereas most coastal bivalves have clear hemolymph with no respiratory pigments, all vesicomyids from chemosynthetic environments known to date are called "blood clams" because of their red hemolymph. Hemolymphs of all five blood clam species analyzed to date contain intracellular hemoglobin (Hb) in erythrocytes (Terwilliger et al. 1983; Suzuki et al. 1989a, 1989b, 2000; Suzuki and Ohta 2000; Zal et al. 2000; Kawano et al. 2003). The blood clam "Calyptogena” magnifica Boss \& Turner 1980, from the hydrothermal vents on the East 
Pacific Rise, has an intracellular hemoglobin $(\mathrm{Hb})$ of $68 \mathrm{kDa}$, which transports oxygen to both host and symbionts (Terwilliger et al. 1983; Zal et al. 2000), while sulfide is carried by a lipoproteic sulfide-binding component dissolved in the hemolymph (Childress et al. 1993; Zal et al. 2000). Hb of this clam, which is exposed to variable environmental conditions, has a relatively high affinity for oxygen (Terwilliger et al. 1983) but may nevertheless greatly facilitate oxygen transport needed for the chemoautotrophic hydrogen sulfide metabolism. Indeed, "C." magnifica lives wedged into fissures of the basaltic rock in a variable environment ranging between that of mixed vent fluid $\left(2.3^{\circ}-14^{\circ} \mathrm{C}, 2-40 \mu \mathrm{M} \mathrm{H}_{2} \mathrm{~S}\right.$, no $\left.\mathrm{O}_{2}\right)$ and the surrounding deep-sea seawater $\left(2^{\circ} \mathrm{C}\right.$, no $\mathrm{H}_{2} \mathrm{~S}$ and $110 \mu \mathrm{M} \mathrm{O}_{2}$; Arp et al. 1984; Fisher et al. 1988; Scott and Fisher 1995). Under such conditions, an oxygen carrier that transports and stores oxygen may favor consistent oxygen delivery to the host and its symbionts, especially if oxygen affinity is independent of the temperature (Terwilliger et al. 1983). To date this is the only vesicomyid $\mathrm{Hb}$ whose functional properties have been analyzed to some extent.

The structure of the intracellular Hbs has been studied in four blood clam species collected from cold seeps around Japan. Phreagena soyoae, "Phreagena" tsubasa, and Abyssogena kaikoi (formerly Calyptogena soyoae, Calyptogena tsubasa, and Calyptogena kaikoi; Krylova and Sahling 2010; Audzijonyte et al. 2012) all have two homodimeric Hbs of $32 \mathrm{kDa}$, termed $\mathrm{HbI}$ and $\mathrm{HbII}$, with more than $90 \%$ sequence identity, revealing their close relationship (Kawano et al. 2003). In $A$. kaikoi both Hbs might also appear as homotetramers, presumably when their concentration is large enough (Suzuki et al. 2000). Moreover, A. kaikoi adductor muscles also contain two cytosolic homodimeric myoglobins $(\mathrm{Mb}), \mathrm{MbI}$ and MbII, which appear to be identical to HbI and HbII dimers, respectively (Suzuki et al. 2000). This identity suggests that the role of $\mathrm{Hbs}$ in A. kaikoi is merely oxygen storage under low oxygen conditions in the deep sea, rather than oxygen transport in the hemolymph (Suzuki et al. 2000). The fourth species, "Calyptogena" nautilei, has two monomeric Hbs of $18 \mathrm{kDa}$, HbIII and HbIV, which have only $33 \%$ and $42 \%$ identity with the sequences of $\mathrm{HbI}$ and $\mathrm{HbII}$, respectively (Kawano et al. 2003). Because all vesicomyid clam species seem to originate from a common ancestor, these sequence variations and their monomeric/dimeric quaternary structures suggest that hemoglobin expression might be influenced by the habitat conditions of each clam species and specifically by oxygen concentration (Kawano et al. 2003).

Christineconcha regab (Krylova and Cosel, 2011) and Laubiericoncha chuni (Thiele and Jaeckel, 1931) are two clam species discovered at the Regab pockmark in the Gulf of Guinea (Olu-Le Roy et al. 2007; Cosel and Olu-Le Roy 2008; Cosel and Olu 2009; fig. 1). Christineconcha regab was formerly described as Calyptogena regab (Cosel and Olu, 2009), but Krylova and Cosel showed that this species differs morphologically from the other Calyptogena and in particular lacks their red hemolymph. Moreover, C. regab is phylogenet- ically separate from the great majority of vesicomyid species (Decker et al. 2012b). In contrast, L. chuni appears to be a true blood clam and is included within a clade of several species from Japan's Trench (Decker et al. 2012b). In the Gulf of Guinea, at the Regab pockmark, C. regab and L. chuni live sympatrically within the same bivalve patches (fig. 1). However, C. regab is abundant and widely distributed all over the pockmark, while L. chuni has been sampled sporadically in its most peripheral southwestern part only. Physicochemical conditions in the Regab pockmark are relatively stable, showing a water temperature of around $2.6^{\circ} \mathrm{C}$ year-round, with an oxygen concentration of about $215-220 \mu \mathrm{mol} / \mathrm{L}$ (Decker et al. 2012a). However, within the sediment, oxygen is present only in the uppermost millimeters, and sulfide concentration can reach $5 \mathrm{mM}$ (Pop Ristova et al. 2012). Sulfides are produced close to the surface, between 3 and $6 \mathrm{~cm}$ depth. Although difficult to measure precisely, the depth of the sulfide peak (or sulfate-methane transition zone) seems to vary at the pockmark scale (Pop Ristova et al. 2012). This implies that vesicomyids have to cope with very hypoxic, almost anoxic conditions to reach sulfides more or less deeply within the sediment.

The aim of this study was to search for oxygen-binding proteins in these two vesicomyid species and to compare their structural and functional properties. We used highperformance liquid chromatography (HPLC) to purify the globins and electrospray ionization mass spectrometry (ESIMS) to analyze their quaternary structure and composition. We measured oxygen-binding properties under various $\mathrm{pH}$ and temperature conditions. These results are discussed in terms of adaptation to hypoxic conditions and in relation to the specific distribution of the two species at the Regab pockmark.

\section{Methods}

\section{Animal Collection}

During three scientific cruises in the Gulf of Guinea, vesicomyid bivalves were collected at the Regab pockmark, $8 \mathrm{~km}$ north of the Congo canyon, at a depth of 3,100 m (Ondréas et al. 2005). The cruises were (1) GUINECO M76/3 cruise in July-August 2008, (2) WACS (West African Cold Seeps) cruise in January-March 2011, and (3) CONGOLOBE cruise in December 2011-January 2012. Vesicomyid specimens were sampled at three different sites within the Regab pockmark: site 1, north (Guineco Marker 3); site 2, center (WACS Marker W05/Guineco Marker 7); and site 3, southwest (WACS Marker W03/Guineco Marker 10; fig. 2). Specimens were collected using a fishing net pulled over the mud surface by a remotely operated vehicle. Two different vesicomyid species were sampled: Christineconcha regab living at all three sites and Laubiericoncha chuni found at site 3 and very occasionally at site 2. After retrieval onboard, the nets with bivalves were quickly transferred to a cold room at $4^{\circ} \mathrm{C}$ before sorting and dissection. 


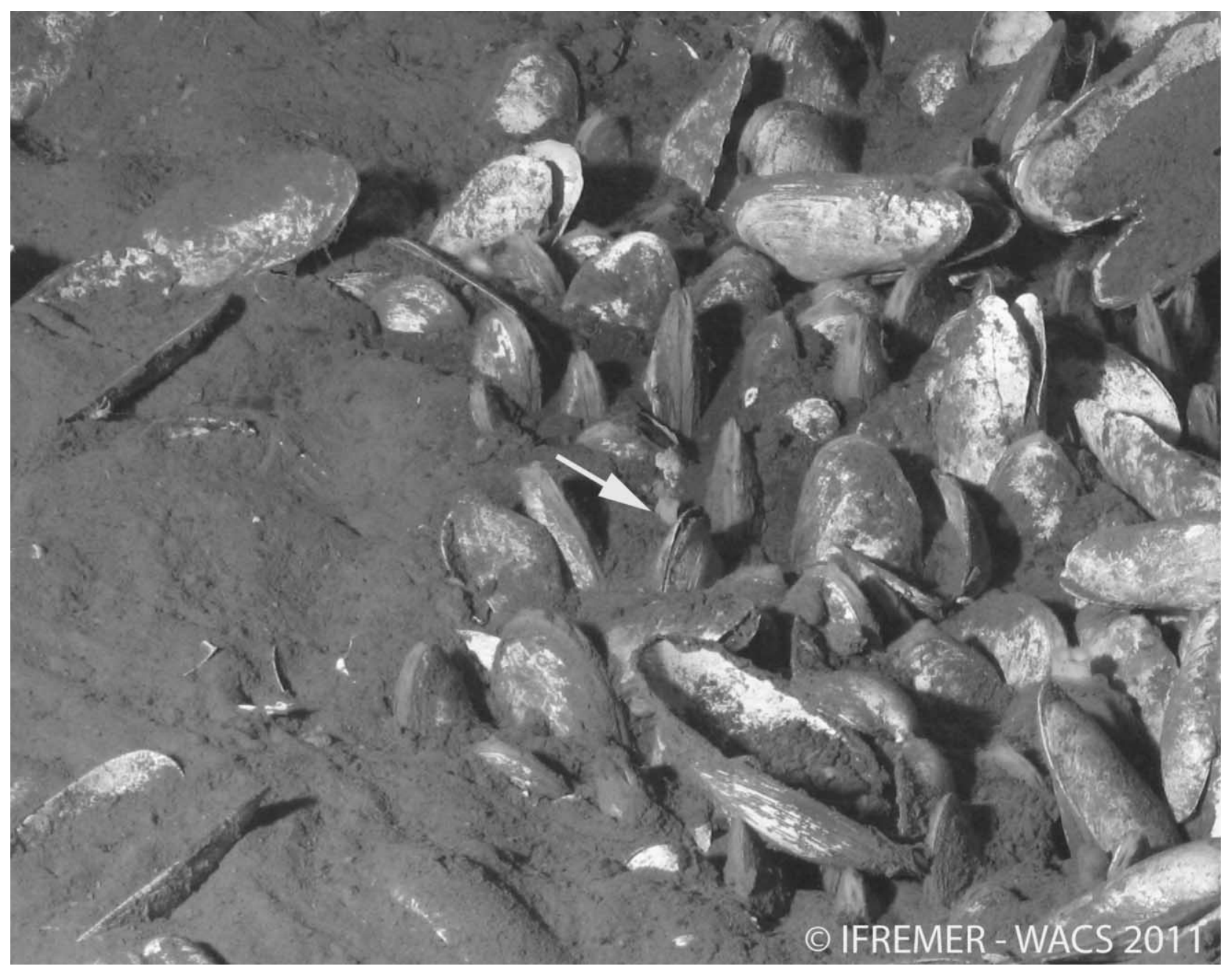

Figure 1. Mixed clam aggregate of Christineconcha regab and Laubiericoncha chuni. The arrow points to L. chuni, from which only the siphons are visible. Photo (C) IFREMER, WACS cruise 2011, ROV Victor 6000.

\section{Hemolymph and Tissue Collection}

Hemolymph was sampled in L. chuni using a 1-mL syringe, inserting the needle between the valves at the anterior end of the clam, or after opening it (table S1, available online), and its foot was also dissected. Because C. regab had no red blood, only the deep red foot was cut after opening of the shells. All samples were frozen in liquid nitrogen and stored at $-80^{\circ} \mathrm{C}$ in the laboratory until use.

\section{Globin Purification by HPLC}

Hemolymph Samples. Hemolymph samples of L. chuni were thawed to lyse the erythrocytes and centrifuged at 10,000 rpm for $10 \mathrm{~min}$ at $4^{\circ} \mathrm{C}$ to recover the $\mathrm{Hb}$. Proteins in the hemolymph were separated by analytical size-exclusion chromatography performed on a Superose 12 10/300 GL Tricorn column (GE Healthcare), with a fractionation range from 1 to $300 \mathrm{kDa}$. The column was equilibrated with a saline HEPES buffer like that prepared for "Calyptogena" magnifica by Childress et al. (1991). The elution rate was $0.5 \mathrm{~mL} / \mathrm{min}$, and the absorbance of the eluate was monitored at 280 and $414 \mathrm{~nm}$, indicative of protein and heme concentrations, respectively. Every hemecontaining protein peak was collected separately and concentrated in microcentrifugal filter devices Centricon-3kDa (Millipore).

Foot Tissue Samples. Feet of C. regab and L. chuni were weighed and crushed in $1 \mathrm{~mL} / \mathrm{g}$ ice-cold HEPES buffer like that prepared by Childress et al. (1991). The homogenate was centrifuged three times at $10,000 \mathrm{rpm}$ for $10 \mathrm{~min}$ at $4^{\circ} \mathrm{C}$, and the supernatant was kept after each centrifugation. When the volume of homogenate was insufficient for analysis, we pooled and crushed the feet of three specimens from the same collection site (table S1). The foot homogenate supernatant of L. chuni was directly purified on serially connected Superose 12 and Superdex 75 columns, the latter with a fractionation range of $3-70 \mathrm{kDa}$. 


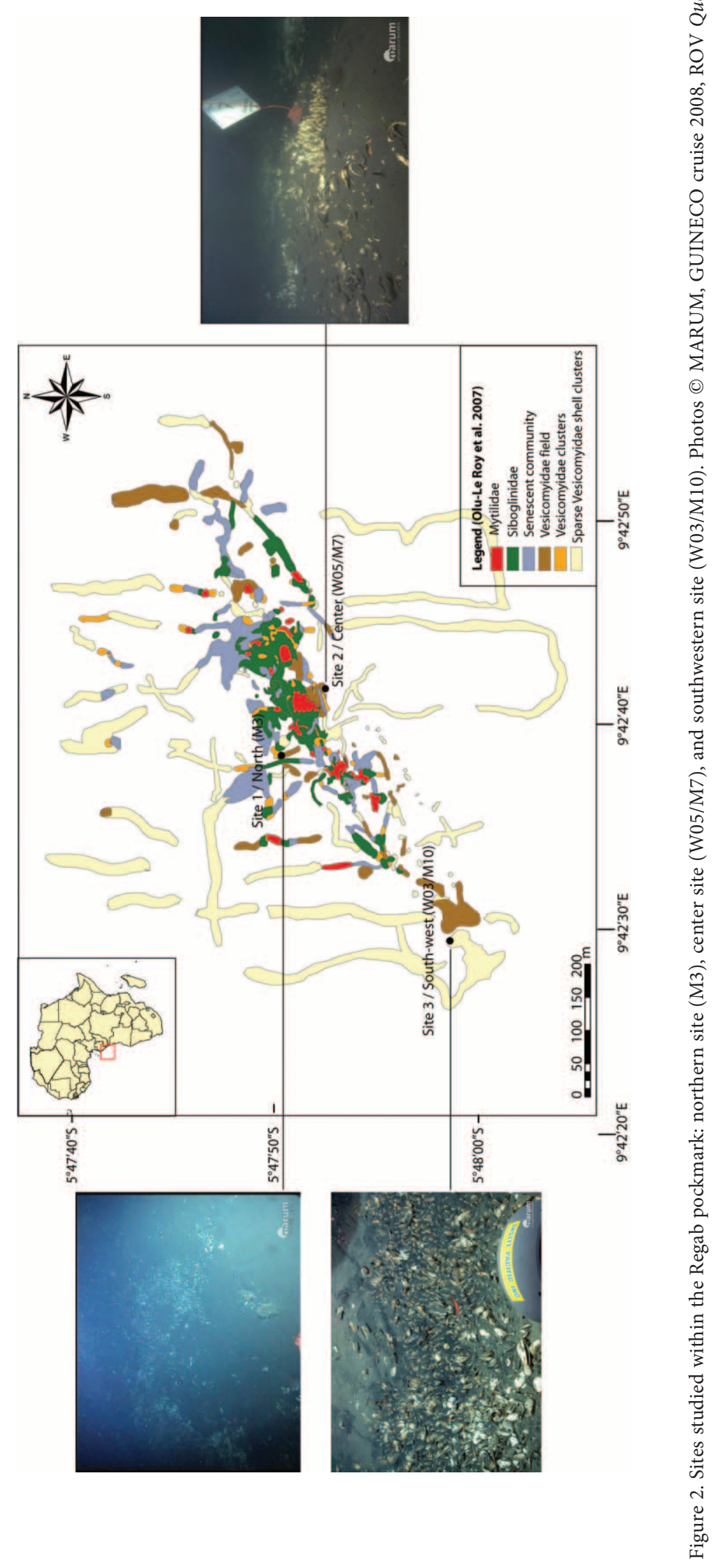


Each heme-containing peak was collected separately and concentrated in a microcentrifugal filter device (Centricon $3 \mathrm{kDa}$, Millipore).

\section{Mass Spectrometry of the Purified Globins}

Samples of hemolymph and foot tissue for mass spectrometry were purified as described previously but in an ammonium acetate buffer at $50 \mathrm{mM}, \mathrm{pH}$ 6.2. ESI-MS analyses were performed in denaturing conditions to search for eventual disulfide bonds and in nondenaturing conditions to preserve the native structure. Ten individuals of each species (L. chuni or C. regab) were analyzed.

For the denaturing analyses, each sample was dissolved at a final concentration of about $0.1 \mathrm{mg} / \mathrm{mL}$ in a mix of water/ acetonitrile/formic acid at 50:50:1 in volume. Mass data were obtained using a MicroTOFLC (Bruker Daltonics, Bremen, Germany) mass spectrometer fitted with Z-spray electrospray ion source and operated in positive ion mode. MS data were acquired from 500 to $2,000 \mathrm{~m} / z$. Mass calibration was performed using a mix of Tune Low (Agilent Technologies G19698500 ) and a solution of horse heart myoglobin at $20 \mathrm{fmol} / \mu \mathrm{L}$ (Sigma, M-1882). Data were processed with Data Analysis software (Bruker Daltonics), and multiple ionized spectra were deconvoluted with the MaxEnt tool to generate molecular mass spectra. All molecular masses were calculated from the raw data multiple ionized peaks.

For nondenaturing analyses, samples were purified using mini-gel filtration columns (Microbiospin 30, Biorad) in 200 or $50 \mathrm{mM}$ ammonium acetate $(\mathrm{pH}$ 7.5). ESI-MS measurements were performed on an electrospray time-of-flight mass spectrometer (MicrOTOF ${ }_{\mathrm{LC}}$, Bruker Daltonics). The capillary exit voltage was set to optimize the desolvation process while preventing dissociation of the noncovalent species (values from 100 to $200 \mathrm{~V}$ were tested). Samples were diluted 10 times in $100 \mathrm{mM}$ ammonium acetate and continuously infused into the ESI ion source at a flow rate of $3 \mu \mathrm{L} / \mathrm{min}$ through a Harvard syringe pump (Harvard Apparatus model 11). Acquisition mass range was 1,000-10,000 mass/charge units. Calibration was performed using a concentrated solution of cesium iodide $(1 \mathrm{mg} / \mathrm{mL}$ in water : isopropanol, $1: 1)$. Masses were calculated and averaged for all ions distributed in the ionized state.

Direct infusion ESI-MS data were complex to interpret, as globin masses were similar and thus generated very close and multiple charged ions. To simplify our interpretations, we had to separate the different globin chains, using reversephase liquid chromatography mass spectrometry. Samples were injected into an HP1100 HPLC (Agilent Technologies). The globins were separated on a 2,1 × $125 \mathrm{~mm}, 5 \mu \mathrm{m}, 300 \AA$, Nucleosil $\mathrm{C}_{18}$ column (Macherey-Nagel) before introduction into the mass spectrometer. Mobile phases were (A) $0.1 \%$ TFA and (B) $0.08 \%$ TFA in acetonitrile. A linear gradient from $5 \% \mathrm{~B}$ to $60 \% \mathrm{~B}$ in $65 \mathrm{~min}$, then to $80 \% \mathrm{~B}$ in $5 \mathrm{~min}$, was used for separation, at a flow rate of $300 \mu \mathrm{L} / \mathrm{min}$. Column temperature was kept at $25^{\circ} \mathrm{C}$. UV trace was monitored at a wavelength of $214 \mathrm{~nm}$, typical for peptide-bond absorption. One-twentieth of the eluted solution coming out of the UV detector was sent to the mass spectrometer by a T-split. The other 19/20 of the solution was manually collected each time a globin was eluted from the column (shown by the UV detector). These collected fractions were systematically reinjected on a MicrOTOF-Q II (Bruker Daltonics) to confirm our LCMS measurements.

\section{Heme-Assay Analyses: Heme and Protein Concentrations}

Ten microliters of purified hemoglobin was diluted in $2 \mathrm{~mL}$ of the purification HEPES buffer (Childress et al. 1991). Ten microliters of potassium ferricyanide solution $(0.01 \mathrm{~mol} / \mathrm{L})$ was added to $2 \mathrm{~mL}$ of this diluted solution and incubated for 5 min at room temperature to oxidize the hemoglobin completely into methemoglobin. Ten microliters of potassium cyanide $(0.05 \mathrm{~mol} / \mathrm{L})$ was then added to obtain the cyanmethemoglobin derivative. The solution was analyzed in a spectrophotometer at $540 \mathrm{~nm}$. Absorbance was measured at $540 \mathrm{~nm}$, and the extinction coefficient of $11.0 \mathrm{~L} / \mathrm{mmol} / \mathrm{cm}$ was used to calculate heme concentration. The Bradford method was used for protein quantification (Bradford 1976).

\section{Oxygen-Binding Measurements}

Oxygen-binding affinities of hemoglobins and myoglobins were obtained in a gas-diffusion chamber (Sick and Gersonde 1969). Small samples (5 $\mu \mathrm{L})$ of purified globin solution were equilibrated with pure $\mathrm{N}_{2}$ for the deoxygenated state and pure $\mathrm{O}_{2}$ for the fully oxygen-saturated state, and mixtures of these gases were added stepwise by the multigas controller MKS 647C (Instruments Deutschland) to determine the partial oxygen pressure $\left(\mathrm{P}_{50}\right)$ corresponding to $50 \% \mathrm{O}_{2}$ saturation. The $\mathrm{pH}$ was measured with a microelectrode Thermo Orion 3 Star (Electron Corporation) on an aliquot of the sample incubated in the water bath, at the same temperature as the measured $\mathrm{P}_{50}$. Oxygenbinding properties and $\mathrm{pH}$ measurements were carried out at $5^{\circ}$, $10^{\circ}$, and $15^{\circ} \mathrm{C}$ for both $\mathrm{Mbs}$ and $\mathrm{Hb}$. Technically, $5^{\circ} \mathrm{C}$ is the lowest possible temperature to measure $\mathrm{P}_{50}$ and avoid water condensation in the sample, so this is the closest possible temperature to the deep-seawater temperature around the clams $\left(2.6^{\circ} \mathrm{C}\right.$; Decker et al. $\left.2012 a\right)$.

Values of $\mathrm{P}_{50}$ and $\mathrm{n}_{50}$ (Hill's cooperativity coefficient at $\mathrm{P}_{50}$ ) were derived from the linear regression of the Hill plots $(\log (S /$ $\left.1-S)=f\left[\log \left(\mathrm{PO}_{2}\right)\right]\right)$ for saturation values in the linear portion of the curve, that is, at saturation values between $30 \%$ and $70 \%$. The Bohr effect was tested on L. chuni hemoglobin and C. regab myoglobin at $5^{\circ} \mathrm{C}$, with $\mathrm{pH}$ values ranging from 5.2 to 7.2. The $\mathrm{pH}$ was adjusted by diluting the hemoglobin solutions with the vesicomyid buffer at the chosen $\mathrm{pH}$ at a ratio of $1: 1$.

\section{Statistical Methods}

Temperature and Bohr effects were tested using nonparametric tests (Wilcoxon-Mann-Whitney test for $n=2$ and 

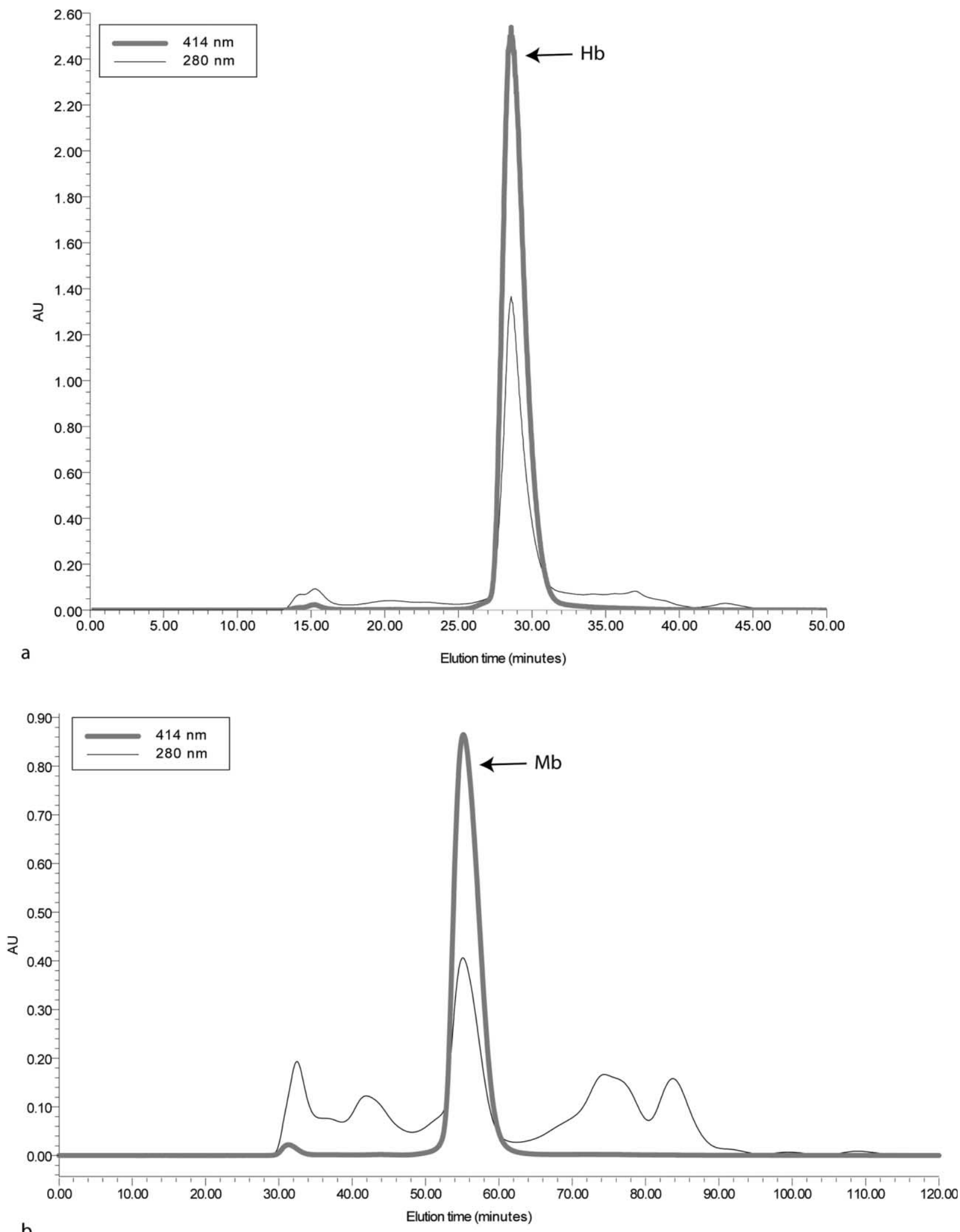

Figure 3. High-performance liquid chromatography spectra of Laubiericoncha chuni hemolymph: (a) hemoglobin (Hb) peak after sizeexclusion chromatography (SEC) filtration on a Superose 12 column and (b) myoglobin $(\mathrm{Mb})$ peak after SEC filtration on Superose 12 and Superdex 75 columns in series. 
Kruskal-Wallis test when $n>2$ ) and a post hoc test: BehrensFisher for nonparametric multiple comparisons. All analyses were performed using the free open-source R Environment (R Development Core Team 2010). The nonparametric multiple comparisons library was used for nonparametric multiple comparisons (Helms and Munzel 2008).

\section{Results}

Structural Analysis of the Globins

Laubiericoncha chuni Circulating Hemoglobin. From 1 to $10 \mathrm{~mL}$ hemolymph was collected per individual of Laubiericoncha chuni. Heme concentration was $0.4 \pm 0.1 \mathrm{mM}(n=3)$. Gel filtration of the hemolymph resulted in a major hemecontaining peak (fig. $3 a$ ). Mass spectrometry was performed on this fraction in order to determine the number of constituents of this heme-protein sample. The expected error on a mass result is about $0.005 \%$ according to ESI-MS instrument specifications. Several mass measurements were performed on each sample, and the results were averaged in order to estimate mass precision. Taken together, percentages of error and precision allowed us to identify similar masses with about 1 Da uncertainty as being identical molecules, termed globins G1, G2, and so forth. The spectra of L. chuni's Hb revealed the presence of three different monomeric globin chains called G1-G3 with experimental masses of 15,361 $\pm 1,15,668 \pm 1$, and 15,682 $\pm 1 \mathrm{Da}$, respectively (table 1; fig. $4 a$ ). In addition, two individuals, one from each site, had a minor covalent homodimeric chain of about 30,724 Da named G1-G1 (figure not shown). The number of constituents in the hemolymph varied between individuals: in particular, G2 was present in the hemolymph of only five out of seven individuals.

L. chuni Foot Myoglobin. The gel filtration of the foot homogenate gave one major fraction corresponding to a heme protein and several nonheme proteins lacking absorption peaks at $414 \mathrm{~nm}$ (fig. $3 b$ ). The second purification on a Superdex

Table 1: Summary of globin chains identified in Laubiericoncha chuni circulating $\mathrm{Hb}$ and foot muscle samples and in Christineconcha regab foot homogenate

\begin{tabular}{|c|c|}
\hline $\begin{array}{l}\text { Species and chains } \\
\text { found in all analyzed } \\
\text { samples }\end{array}$ & Chains specific to \\
\hline \multicolumn{2}{|l|}{ L. chuni: } \\
\hline $\mathrm{G} 1: 15,361 \pm 1 \mathrm{Da}$ & Foot muscle: G4: $14,786 \pm 1 \mathrm{Da}$ \\
\hline G3: $15,682 \pm 1 \mathrm{Da}$ & Circulating Hb: G2: $15,668 \pm 1 \mathrm{Da}$ \\
\hline \multicolumn{2}{|l|}{ C. regab: } \\
\hline $\mathrm{G} 1^{\prime}: 15,139 \pm 1 \mathrm{Da}$ & Site 1: G3': $15,683 \pm 1 \mathrm{Da}$ \\
\hline & Site 2: $\mathrm{G}^{\prime} 1-\mathrm{G}^{\prime} 1: 30,278 \pm 1 \mathrm{Da}$ \\
\hline & $\mathrm{G}^{\prime} 2-\mathrm{G}^{\prime} 2: 30,340 \pm 1 \mathrm{Da}$ \\
\hline & Sites 2 and 3: G2': 15,169 $\pm 1 \mathrm{Da}$ \\
\hline
\end{tabular}

75 enabled us to collect a single pure heme-protein fraction. Mass spectrometry performed on this heme fraction revealed three monomeric chains (table 1; fig. 4b). Two chains had masses identical to G1 and G3 from the purified hemolymph. The last globin chain (G4) was lighter, with a mass of $14,786 \pm 1 \mathrm{Da}$. In order to determine the stoichiometry, nondenaturing mass spectrometry was performed. The ESI-MS conditions were optimized using a solution of human hemoglobin. While human hemoglobin reference was observed as an $\alpha 2 \beta 2$ tetramer, as expected, masses of $L$. chuni's globins corresponded to those of monomers bound to a single heme unit at 15,401 $\pm 1 \mathrm{Da}$ for G4, 16,297 $\pm 1 \mathrm{Da}$ for G3, and 15,977 \pm $1 \mathrm{Da}$ for G1 (fig. 5). Comparing the masses of the globins found in the circulating blood (fig. 4a) with those found in the foot extract (fig. $4 b$ ) of L. chuni, globin G2 appears specific to hemolymph, whereas G4 appears to be specific to muscle, but globins G1 and G3 are found in both hemolymph and muscle.

Christineconcha regab Foot Myoglobin. As for L. chuni foot homogenate, the gel filtration of $C$. regab's Mbs provided one major fraction and several nonheminic proteins (fig. 6a). The second purification of the heme proteins allowed an apparent complete elimination of the nonheminic proteins (fig. 6b).

Mass spectrometry analyses on the final purification of the second fraction revealed three different monomeric chains of $15,139 \pm 1 \mathrm{Da}\left(\mathrm{G} 1^{\prime}\right), 15,169 \pm 1 \mathrm{Da}\left(\mathrm{G} 2^{\prime}\right)$, and 15,683 \pm 1 $\mathrm{Da}\left(\mathrm{G} 3^{\prime}\right)$. The globin chain $\mathrm{G} 1^{\prime}$ was found in all specimens from all sites, whereas $\mathrm{G} 2{ }^{\prime}$ was present only in specimens from the central and southwestern sites and chain G3' in specimens from the northern site (table 1). Some of these monomeric chains ( $\mathrm{G} 1^{\prime}$ and $\mathrm{G} 2^{\prime}$ ) were also found in their oxygenated state (results not shown). Two homodimeric chains of $\mathrm{G1}^{\prime}-\mathrm{G} 1^{\prime}$ and $\mathrm{G} 2^{\prime}-\mathrm{G} 2^{\prime}$ were also observed in two specimens from the central site (table 1).

\section{Oxygen-Binding Properties}

Oxygen-binding properties were measured on the purified Hbs and Mbs of L. chuni (table 2). At $5^{\circ} \mathrm{C}$, the value of the $\mathrm{P}_{50}$ was significantly higher for circulating $\mathrm{Hb}(0.45 \pm 0.18$ Torr at $\mathrm{pH}$ $6.65 \pm 0.07, n=3)$ than for foot $\mathrm{Mb}(0.19 \pm 0.02$ Torr at $\mathrm{pH}$ $6.27 \pm 0.4, n=3$; Wilcoxon Mann-Whitney, $W=9, P<0.08)$. Consequently, the oxygen affinity is higher for cytosolic $\mathrm{Mb}$ than for circulating $\mathrm{Hb}$ in L. chuni. As expected for monomeric globins, there was no cooperativity in any of the molecules as $n_{50}$ was close to 1 (table 2).

A slight temperature effect was observed for the hemoglobin, with a tendency of the affinity to decrease with a temperature increase from $5^{\circ}$ to $15^{\circ} \mathrm{C}$ (fig. $7 a$ ), although it was not statistically significant in our sampling (Kruskal-Wallis: $\chi^{2}=$ 4.7, $P=0.1$ ). Foot myoglobin affinity remained stable with an increase in temperature (Kruskal-Wallis: $\chi^{2}=3.7, P=0.2$; fig. 7a). Variation in $\mathrm{pH}$ had no effect on hemoglobin affinity (fig. $7 b$; Kruskal-Wallis, $\chi^{2}=13.37, P=0.42$ ). 


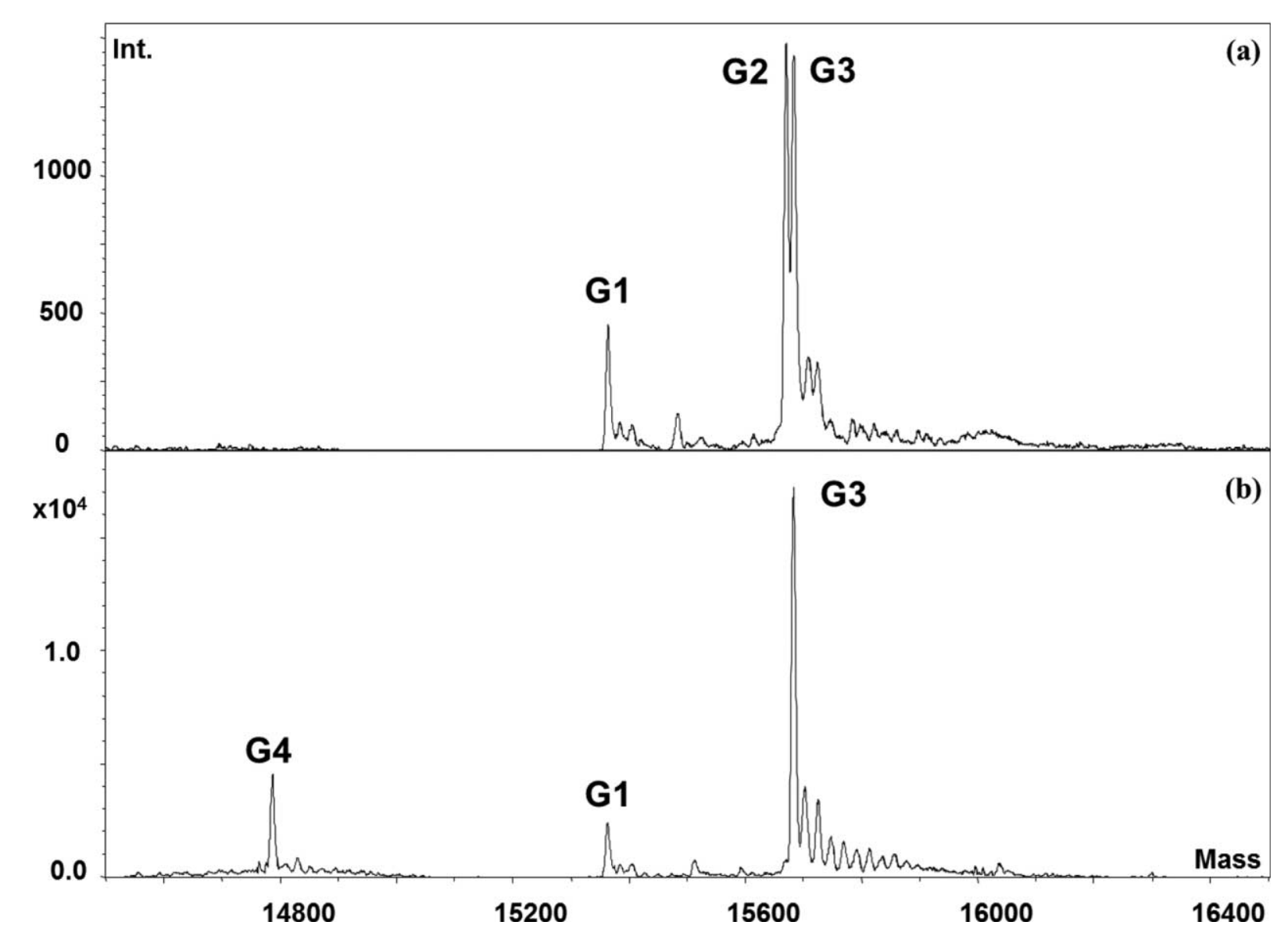

Figure 4. Comparison between (a) Laubiericoncha chuni circulating hemoglobin and (b) L. chuni foot myoglobin (MaxEnt deconvolution spectra). Masses calculated on multiply charged spectrum were (a) G1: 15,361.3 \pm 0.3 Da; G2: 15,668.3 $\pm 0.2 \mathrm{Da}$; G3: $15,682.4 \pm 0.3 \mathrm{Da}$ and (b) G1: $15,362.8 \pm 0.2 \mathrm{Da}$; G3: $15,682.1 \pm 0.5 \mathrm{Da} ; \mathrm{G} 4: 14,786.8 \pm 0.2 \mathrm{Da}$.

Christineconcha regab myoglobin affinity was about 0.85 Torr \pm 0.09 at $\mathrm{pH}=6.63$ and $T=5^{\circ} \mathrm{C}(n=3)$, and with this high value its affinity was lower than the affinity of L. chuni $\mathrm{Mb}$ and $\mathrm{Hb}$ (Wilcoxon Mann-Whitney: $W=9, P<$ 0.08 ). As for L. chuni, no cooperativity was measured (table 2 ), and a decrease in affinity was observed with an increase in temperature (fig. 8a), but no Bohr effect was observed (fig. 8b).

\section{Discussion}

At the Regab pockmark, the dominant species, Christineconcha regab, is the first recorded vesicomyid clam from a chemosynthetic environment with clear hemolymph (i.e., that is not a "blood clam"). However, the deep red foot of this species contains myoglobin. The other vesicomyid clam found at Regab, Laubiericoncha chuni, is a regular blood clam having both intracellular circulating hemoglobin and myoglobin in its foot muscle. Both species also have deep red adductor muscles, probably also containing $\mathrm{Mb}$.

\section{L. chuni and C. regab Have Monomeric Globins}

In $L$. chuni, both circulating $\mathrm{Hb}$ and cytosolic $\mathrm{Mb}$ are monomeric globins of about $15 \mathrm{kDa}$. A monomeric structure is also found in the vesicomyid "Calyptogena" nautilei from Japan's trench, but its molecular mass is higher-about $18 \mathrm{kDa}$, as determined from cDNA sequence (Kawano et al. 2003). In fact, compared to the stable molecular mass of vertebrate globins, that of invertebrates varies much more: from 14 to 19 $\mathrm{kDa}$ (Weber and Vinogradov 2001; Bruneaux et al. 2008). Thus, our results fit within the normal mass range for invertebrate globins. The three other cold seep vesicomyid species likely have globins of about $15-16 \mathrm{kDa}$, but they are associated as homodimers (Suzuki et al. 1989b; Suzuki and Ohta 2000; Kawano et al. 2003).

In our sampling of L. chuni, hemolymph has two or three types of globin monomers of slightly increasing masses that apparently do not dimerize naturally. $\mathrm{As} \mathrm{Hb}$ is circulating through the blood vessels and capillaries irrigating the foot muscle, it might be difficult to sort out the circulating globins from the cytosolic muscle globins, and this might explain the similarity of the globins found in both hemolymph and foot muscle. However, G4, with a lighter mass of about $14 \mathrm{kDa}$, is observed only in the foot muscle and thus seems to be a specific cytosolic Mb, whereas globin G2, when present, is found only as circulating $\mathrm{Hb}$. In purified circulating $\mathrm{Hb}$, the lightest chain (G1) can form a homodimer. This covalent homodimer is probably due to the presence of cysteine residues 


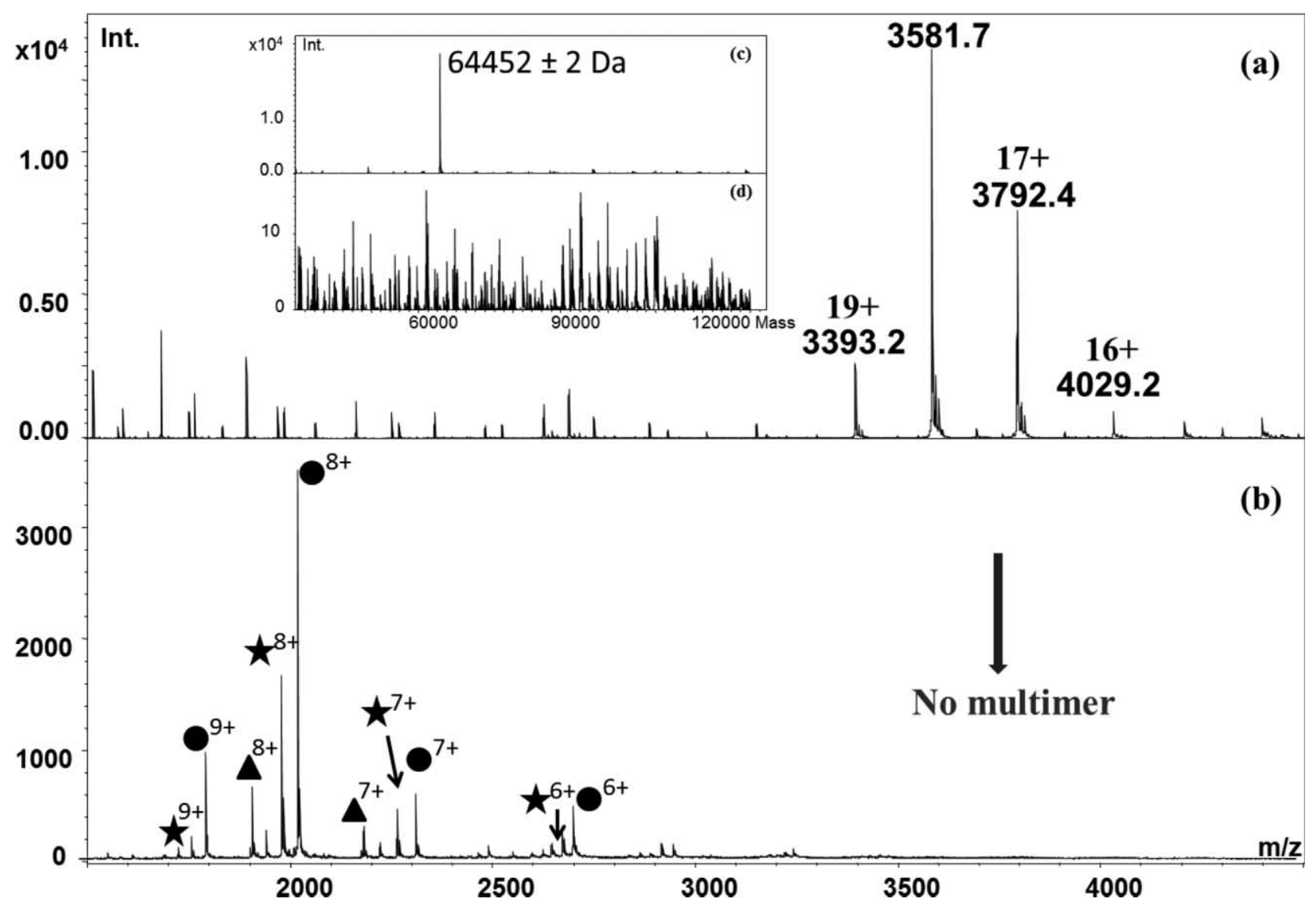

Figure 5. Comparison of nondenaturant electrospray ionization mass spectrometry between $(a, c)$ human hemoglobin and $(b, d)$ Laubiericoncha chuni foot myoglobin ( $a, b$, multiply charged spectra; $c, d$, MaxEnt deconvolution spectra). The human sample showed tetrameric $\alpha 2 \beta 2$ hemoglobin, as expected (essentially with $16,17,18$, and $19 \mathrm{H}^{+}$), whereas no multimeric form was found in the samples of $L$. chuni. The masses obtained for L. chuni's globins show that they are associated with their heme molecule: triangles, 15,401 \pm 1 Da: G4 + heme; circles, $16,297 \pm$ 1 Da: G3 + heme; stars, 15,977 $\pm 1 \mathrm{Da}$ : G1 + heme (charges from 6 to $9 \mathrm{H}^{+}$).

in the primary sequence, forming disulfide bridges between two globin chains, which has to be confirmed by sequencing. On the contrary, no dimerization is observed in L. chuni's foot homogenate. In L. chuni and C. regab, the number of globin chains of different masses vary according to the specimens. Having various globins within an organism might enable a finetuning of the $\mathrm{O}_{2}$ binding, as the various globins might differ in their $\mathrm{O}_{2}$ affinities or in other functional properties. Moreover, most of the bivalves possess two hemoglobins, one with a higher affinity than the second one (Nagel 1985; Weber and Vinogradov 2001). The globin diversity within an organism could thus enable a modulation of the oxygen affinity even as monomers, to fit to the oxygen levels of the surrounding environment. This diversity could either result from a structural genetic diversity at the population level or come from modulations in the transcription of the globin genes, due to individual metabolic variations and/or due to environmental changes. The latter hypothesis has previously been assessed for the differential expression of globin messenger RNA in the vent tubeworm Ridgeia piscesae, according to its habitats: on the hot anoxic vent chimney, the short, wide Ridgeia morphotype shows levels of gene expression up to 12 times greater and also much higher Hb concentrations compared to the long, thin Ridgeia morphotype living in the cooler and more oxygenated surrounding basaltic fields (Carney et al. 2007). In a comparable way, as we observed differences between sampling sites, we may hypothesize that, triggered by the oxygen conditions in their surrounding microhabitat, the vesicomyids could express different proportions of their various globin monomers to regulate the bivalve's oxygen supply and storage at a fine level.

\section{L. chuni and C. regab Globin Functional Properties}

Coastal and shallow-water bivalves from the Arcidae family having intracellular $\mathrm{Hb}$ show oxygen affinities, measured within the same $\mathrm{pH}$ range of $6.8-7$ and at a temperature of $20^{\circ} \mathrm{C}$, that vary according to the species from 7.8 to about 33 Torr (Nagel 1985; Chiancone et al. 1993; Weber and Vinogradov 2001). The globins of the two vesicomyid species we analyzed show a very high affinity $\left(\mathrm{P}_{50}<1\right.$ Torr from $5^{\circ}$ to $15^{\circ} \mathrm{C}$ at $\mathrm{pH}$ about 7.5) for circulating hemoglobin and foot myoglobin, with a significantly higher affinity for $L$. chuni globins than for $C$. regab $\mathrm{Mb}$, despite slight individual variations. These 

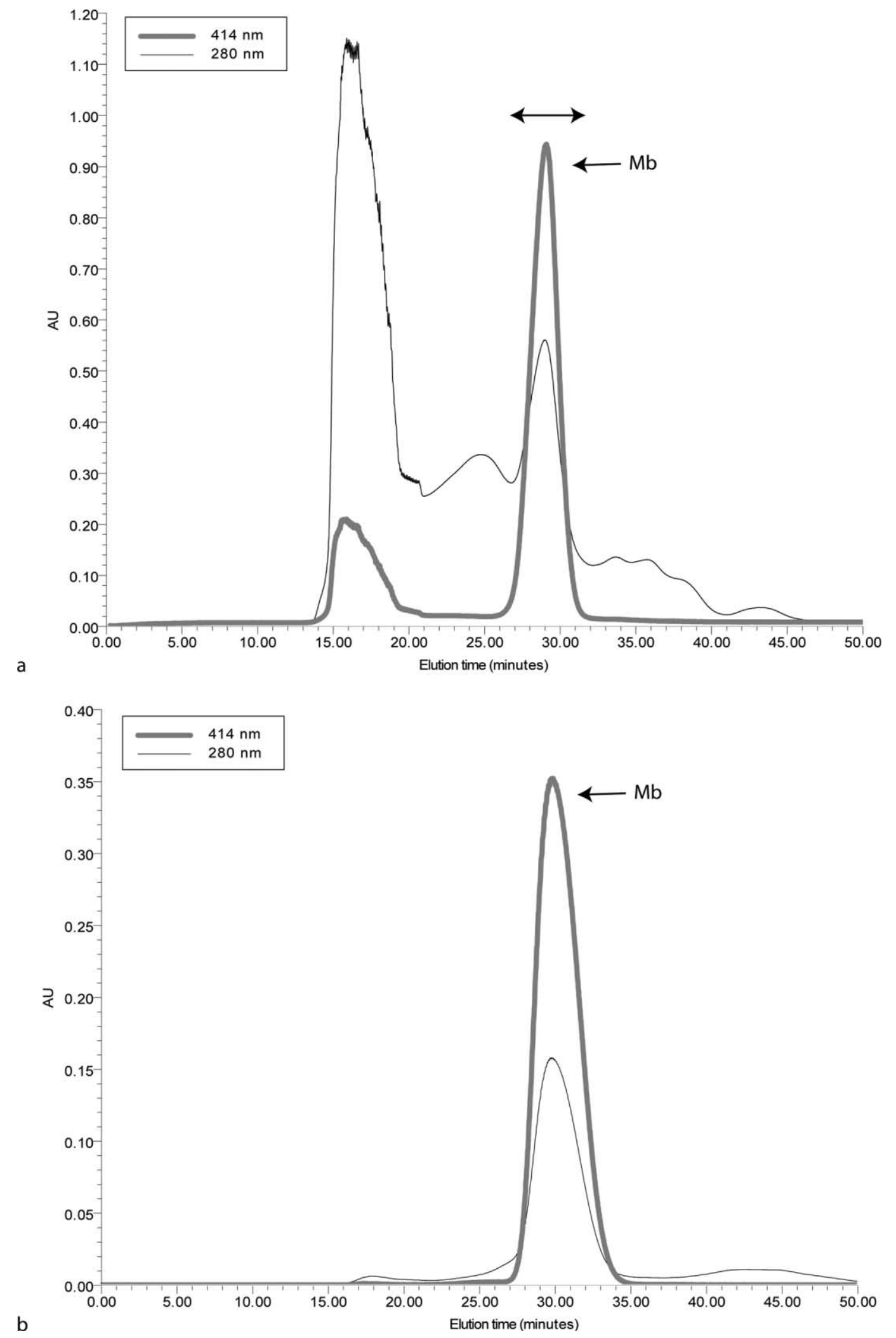

Figure 6. $a$, Elution profile of Christineconcha regab myoglobin $(\mathrm{Mb})$ after size-exclusion chromatography on a Superose $12 . b$, Arrows show the collected peak then purified on a Superdex 75. Both columns were equilibrated with the vesicomyid buffer (pH 6.2) described in Childress et al. (1991). 
Table 2: Oxygen-binding properties of Laubiericoncha chuni hemoglobin and myoglobin and Christineconcha regab myoglobin at $5^{\circ} \mathrm{C}$

\begin{tabular}{llll}
\hline $\begin{array}{l}\text { Species, type, and } \\
\text { specimens or samples }\end{array}$ & \multicolumn{1}{c}{$\mathrm{pH}$} & \multicolumn{1}{c}{$\mathrm{P}_{50}$} & $\mathrm{n}_{50}$ \\
\hline L. chuni: & & & \\
Hemoglobin: & & & \\
425-V1 & 6.7 & .26 & .83 \\
$425-\mathrm{V} 2$ & 6.57 & .48 & .91 \\
425-V3 & 6.67 & .61 & .71 \\
Mean (SD) & $6.65(.07)$ & $.45(.18)$ & $.82(.1)$ \\
Myoglobin: & & & \\
Lc1 & 6.02 & .17 & 1 \\
Lc2 & 6.05 & .2 & 1.09 \\
Lc3 & 6.74 & .2 & 1.55 \\
Mean (SD) & $6.27(.40)$ & $.19(.02)$ & $1.20(.29)$ \\
C. regab: & & & \\
Myoglobin: & & & .98 \\
Chr1 & 6.78 & .95 & .92 \\
Chr2 & 6.55 & .8 & .82 \\
Chr3 & 6.55 & .79 & $.91(.08)$ \\
Mean (SD) & $6.63(.13)$ & $.85(.09)$ & \\
& & &
\end{tabular}

values are thus among the highest levels found in bivalve $\mathrm{Hb}$ but within the range of $0.1-3$ Torr for the globin affinities of the symbiotic bivalves living in reduced (shallow-water) sediments, such as solemyids and lucinids (Terwilliger and Terwilliger 1985; Kraus et al. 1996; Weber and Vinogradov 2001). In particular, Solemya reidi has an intracellular $\mathrm{Hb}$ with a $\mathrm{P}_{50}$ of about $0.3-0.5$ Torr at $\mathrm{pH} 7.5$ and $20^{\circ} \mathrm{C}$ (Kraus et al. 1996), which is similar to the values we measured in the two seep vesicomyids. Within the same $\mathrm{pH}$ and temperature conditions, the affinity of the branchial cytosolic globins of Lucina pectinata is even higher since the $\mathrm{P}_{50}$ is about 0.1 Torr (Kraus and Wittenberg 1990). Compared at the same temperature of $10^{\circ} \mathrm{C}$ and within the same $\mathrm{pH}$ range, the value for L. chuni's monomeric $\mathrm{Hb}$ is 0.22 Torr and corresponds, surprisingly, to a much higher affinity than that of the tetrameric Hb of the vent clam "Calyptogena" magnifica $\left(\mathrm{P}_{50}=7.6 \pm 0.23\right.$ Torr at $\mathrm{pH} 6.78$ and $10^{\circ} \mathrm{C}$; Terwilliger et al. 1983). However, a tetrameric $\mathrm{Hb}$ transports four times more $\mathrm{O}_{2}$ per molecule than a monomer, but the oxygen supply ultimately relies on their respective heme concentration in the hemolymph, that is, from 0.1 to $0.4 \mathrm{mM}$ in L. chuni, which seems rather comparable to those measured in "C." magnifica $(<0.4 \mathrm{mM}$; Powell and Arp 1989). Although tetrameric, the vent clam $\mathrm{Hb}$ has a low cooperativity $\left(\mathrm{n}_{50}=1.24\right)$, and both the affinity and the cooperativity vary little with a temperature increase from $2^{\circ}$ to $11^{\circ} \mathrm{C}$ (Terwilliger et al. 1983). These figures contrast with the properties found in the monomeric $\mathrm{Hb}$ of L. chuni. The globins of L. chuni and C. regab do not show any cooperativity $\left(\mathrm{n}_{50}=1\right)$ at all the temperatures tested, and no Bohr effect, that is, no decrease in affinity when the $\mathrm{pH}$ drops, aligns with the monomeric state of the globins that do not interact in the hemolymph. This is also consistent with what is observed in most bivalves' red blood cell $\mathrm{Hb}$ (Weber and Vinogradov 2001). Functionally, it means that a $\mathrm{pH}$ drop in the tissues when they become acidic will not result in an increase in oxygen delivery from the globins to the tissues.

On the contrary, when the temperature increases, the affinity of $\mathrm{Hb}$ in L. chuni drops. However, based on the exothermic nature of heme oxygenation, $\mathrm{P}_{50}$ must increase at higher temperatures. The heat or enthalpy change $(\Delta H)$ due to the oxygen binding on the globins can be directly derived from the integrated Van't Hoff equation: $\Delta H=-2.303 \mathrm{R} \times \Delta \log$ $\mathrm{P}_{50} / \Delta(1 / T)$, where $\mathrm{R}$ is the universal gas constant and $T$ is the absolute temperature. Using this equation, we have calculated the enthalpy of the $\mathrm{Hb}-\mathrm{O}_{2}$ complex derived from our $\mathrm{P}_{50}$ data, at various temperatures. Between $5^{\circ}$ and $15^{\circ} \mathrm{C}$, at $\mathrm{pH} 7.5$, the enthalpy changes for the $\mathrm{Hb}$ of $L$. chuni are $-69 \mathrm{~kJ} / \mathrm{mol}$. Moreover, this high negative value is consistent with the absence of the Bohr effect, as oxygenation-linked proton dissociation is endothermic and would lower the overall enthalpy value. Comparatively, the heat liberated upon oxygen binding to alpha or beta human $\mathrm{Hb}$ monomers alone is about $-66 \mathrm{~kJ} /$ mol (Ackers 1980). Our enthalpy value is very close to that value and also comparable to that from the large $\mathrm{Hb}$ molecules in the pulmonate mollusc Biomphalaria glabra $(\Delta H=-49$ to $-77 \mathrm{~kJ} / \mathrm{mol}$; Bugge and Weber 1999) and that in a hydrothermal copepod $(\Delta H=-68.7 \mathrm{~kJ} / \mathrm{mol}$; Hourdez et al. 2000).

Oxygen affinity is higher in L. chuni (circulating hemoglobin and foot myoglobin: 0.45 and 0.19 Torr, respectively) than in C. regab (0.85 Torr). It is noteworthy that the affinity of the myoglobin in L. chuni is particularly high, even higher than that of the circulating $\mathrm{Hb}$ and surprisingly less variable to temperature differences (as there is no Bohr effect to create an endothermic dissociation of protons to compensate for the natural exothermic oxygen binding to the heme). The higher oxygen affinity in the $\mathrm{Mb}$ than in the $\mathrm{Hb}$ indicates a biologically advantageous oxygen transfer from $\mathrm{Hb}$ to $\mathrm{Mb}$ to enable oxygen storage in the muscle, as found in vertebrate animals and described in literature for some invertebrates that have both these pigments (Wittenberg 1970). The high affinity of $\mathrm{Mb}$ to oxygen might also indicate a great importance of binding oxygen within the foot, in particular during sulfide uptake from the sediments, to avoid oxidation of sulfides before they are transported through the hemolymph and reach the symbionts, in the gills.

In conclusion, the two sympatric species at the cold seep pockmark Regab vary greatly in their methods of bringing oxygen to their symbionts: C. regab transports the oxygen dissolved in its hemolymph as a regular coastal bivalve, whereas L. chuni has a greatly enhanced transport capacitance, with its $\mathrm{Hb}$ as oxygen carrier within red blood cells, like all blood clams. In fact, $\mathrm{Hb}$ can ensure both the oxygen transport and its storage in the hemolymph during hypoxic periods when the clam remains closed or when a greater oxygen demand occurs during burying. This oxygen storage might enable L. chuni to 


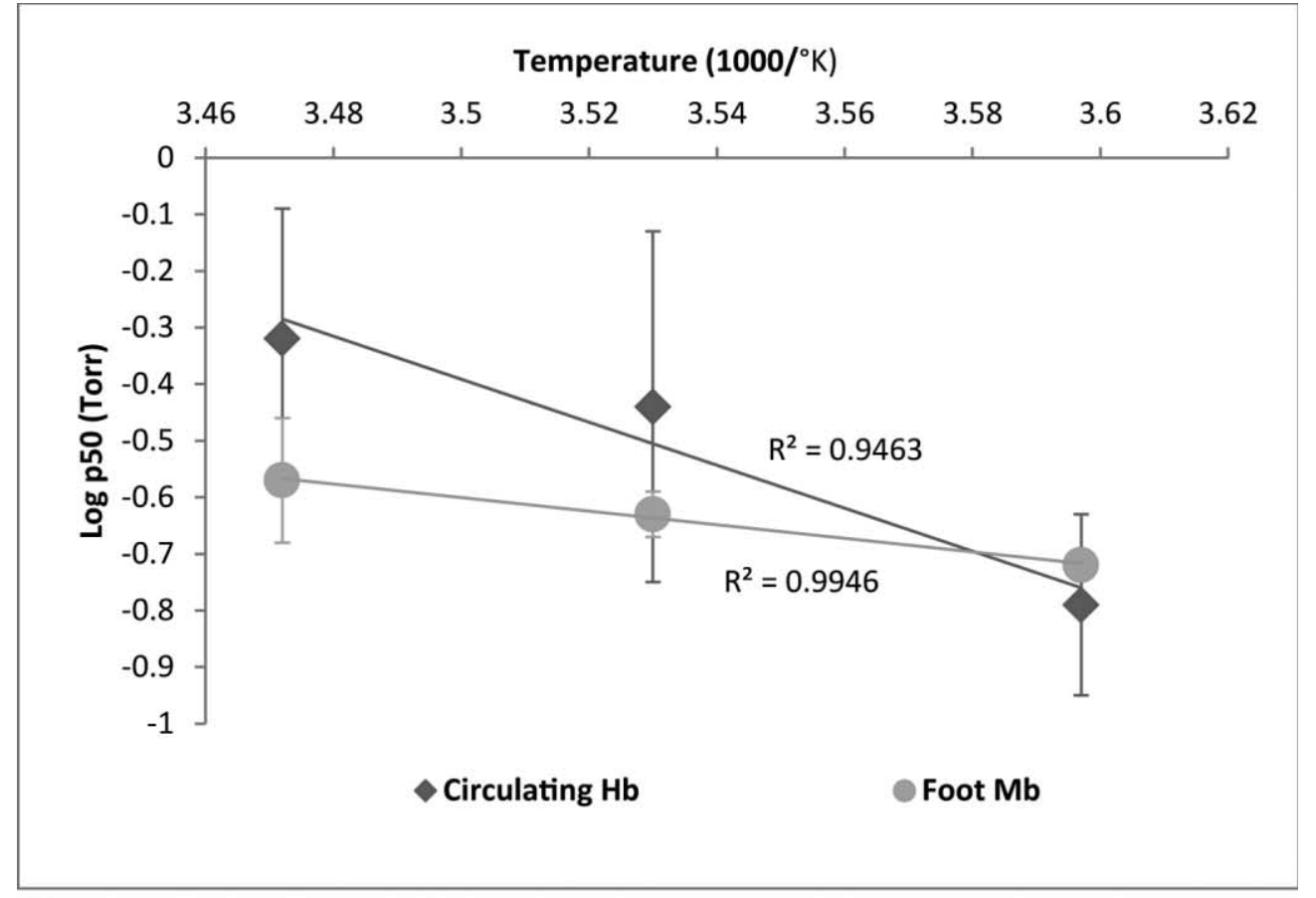

a

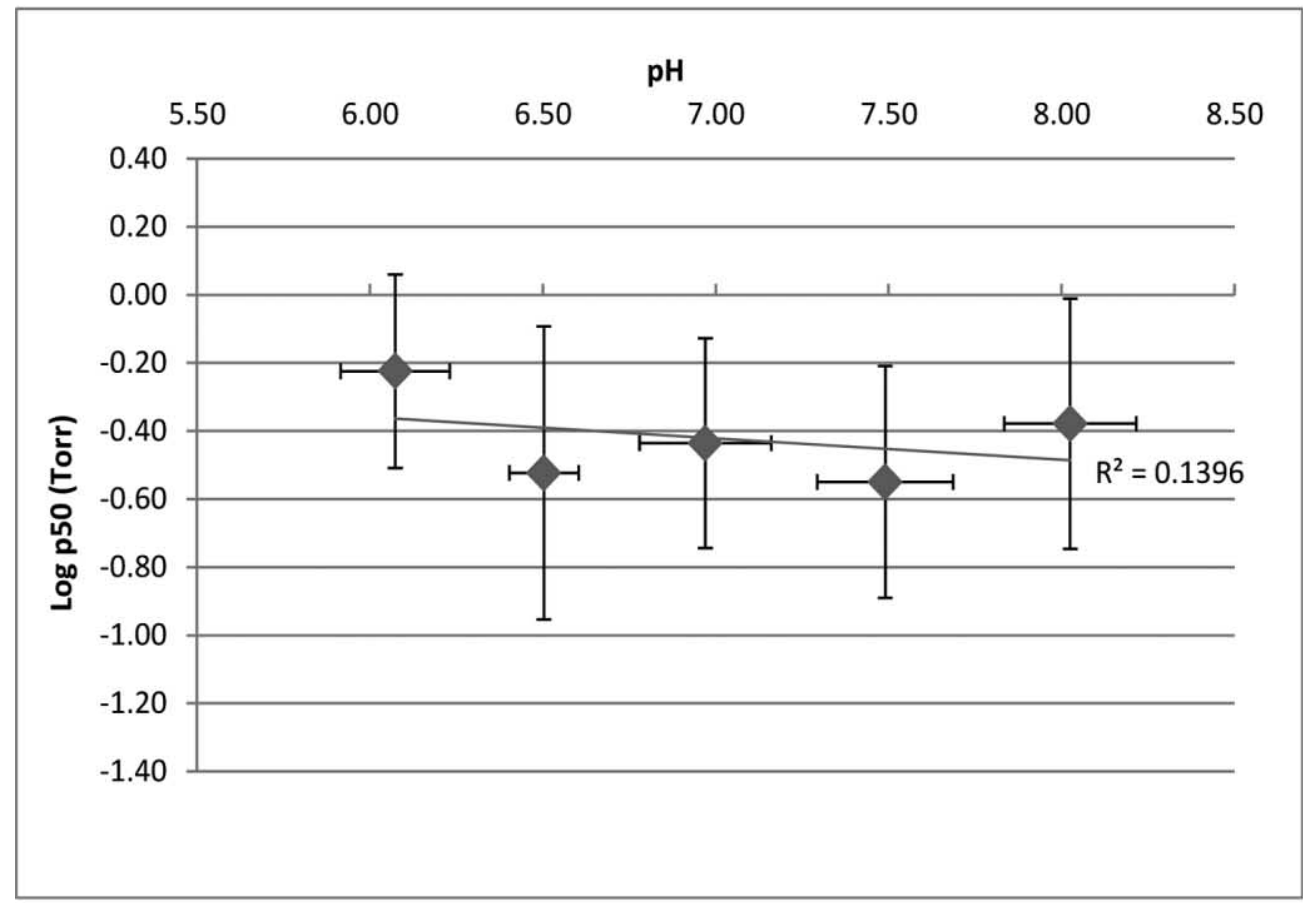

b

Figure 7. Temperature effect on Laubiericoncha chuni hemoglobin ( $\mathrm{Hb})$ and foot myoglobin $(\mathrm{Mb} ; a)$ and Bohr effect on L. chuni hemoglobin $(b)$.

bury deeper into the sediment to reach a larger source of sulfides. This hypothesis would be in favor of the deep position of $L$. chuni, whose siphons are only rarely seen at the sediment surface, while it could nonetheless ensure an aerobic metabolism. This also could explain the distribution of both species along the pockmark according to the depth of sulfide production. Indeed, L. chuni is more abundant in the southwestern part of the pockmark (site 3), where the lower methane fluxes (Decker et al. 2012a; Pop Ristova et al. 2012) and higher maximum rates of anaerobic oxidation of methane (Pop Ristova et al. 2012) may drive sulfide production deeper in the sediment than at the most active central venting site 2 , 


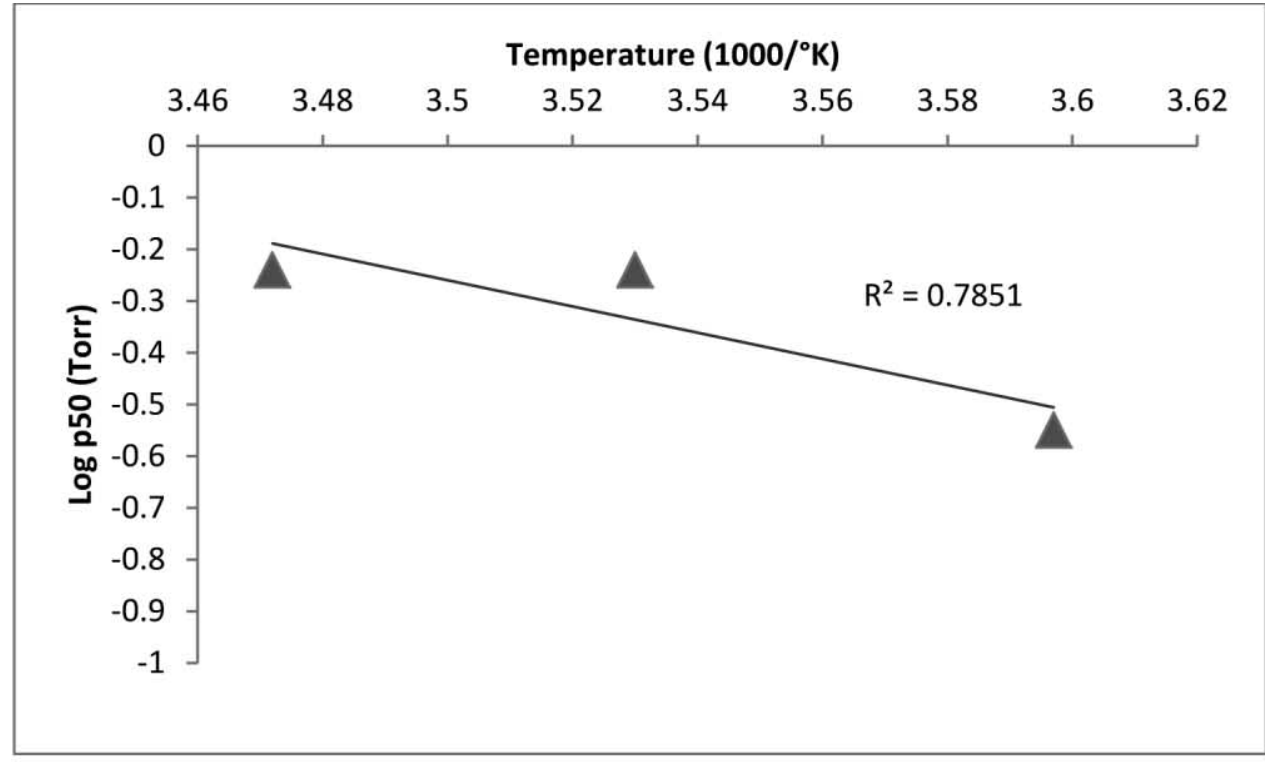

a

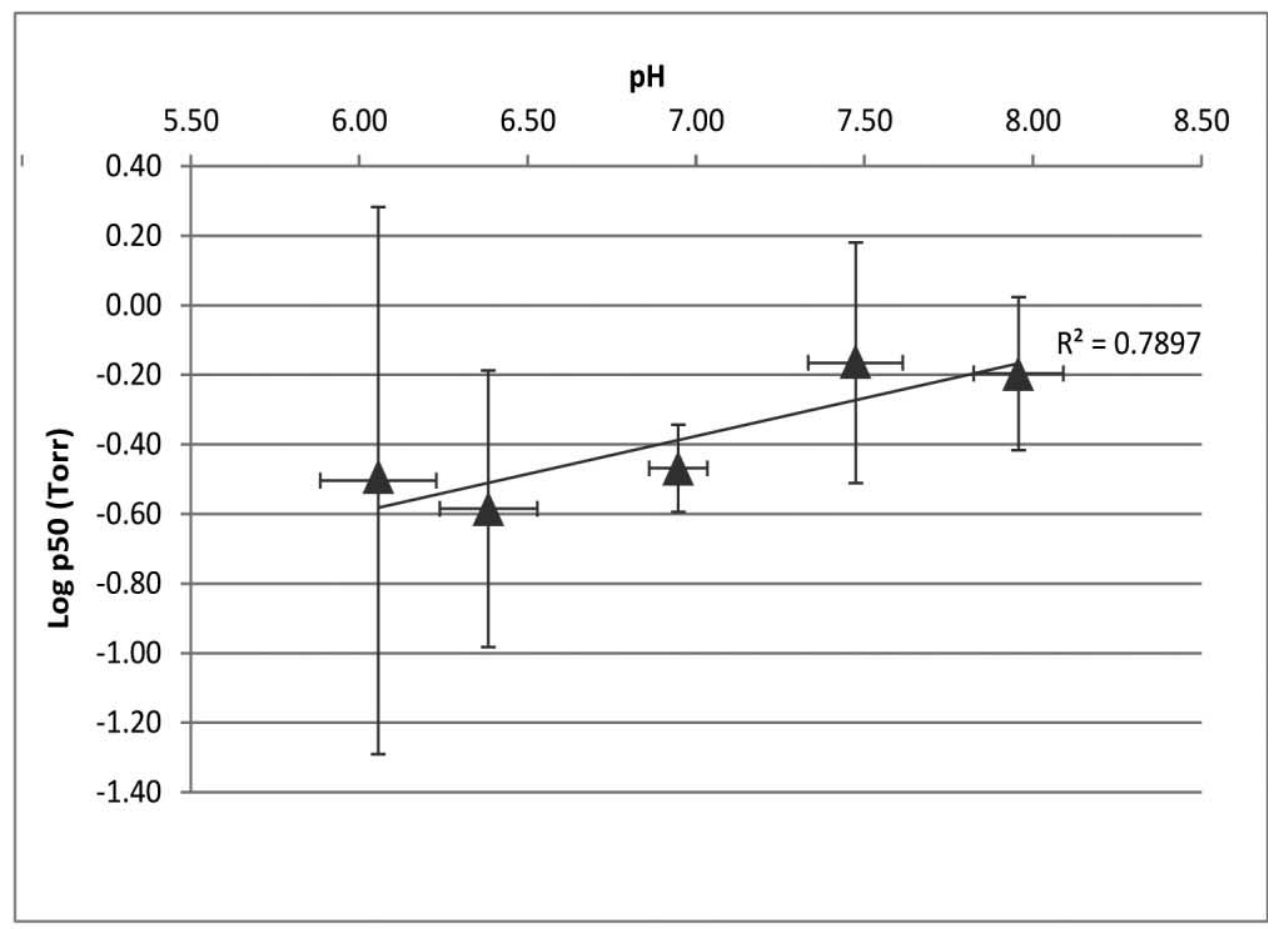

b

Figure 8. Temperature effect on Christineconcha regab foot myoglobin (a) and Bohr effect on C. regab myoglobin (b).

as observed at other seep sites (Fischer et al. 2012). Whether its $\mathrm{Hb}$ could bind sulfide like that of the lucinids and solemyids (Kraus 1990; Kraus et al. 1996) remains to be investigated. However, it is possible that the great molecular mass molecule, eluted in the void volume of the column during the purification of the hemolymph, could be a sulfide-binding component comparable to the sulfide-binding lipoprotein isolated in "Calyptogena" magnifica (Zal et al. 2000).
Compared to the majority of blood clams found at vents and seeps, it is questionable how C. regab can cope without $\mathrm{Hb}$ in its hemolymph. It might be explained by its different symbionts, which could have a different energy metabolism (Decker et al. 2013), or simply because this species always positions its shell and siphons well above the sediment's surface to avoid hypoxy and get enough oxygen. It would be interesting to see whether hypoxic conditions would lead to 
anaerobic metabolism in this species. Nevertheless, C. regab's foot myoglobin provides a supply of oxygen during its burying or moving laterally to find areas richer in sulfides.

\section{Acknowledgments}

We are indebted to the people who provided us with the vesicomyid samples, including the chief scientists of the three cruises: Dr. Antje Boetius (GUINECO M76/3 2008), Dr. K. Olu (WACS 2011), and Dr. Christophe Rabouille (CONGOLOBE 2011-2012). We thank the pilots and crew of the research vessel Meteor with the remotely operated vehicle (ROV) QUEST 4000 and of the N/O Pourquoi Pas? with the ROV Victor 6000, for the two latter cruises. We would like to thank Dr. Stéphane Hourdez for his valuable discussions about the results and both Dr. Franck Zal and Dr. André Toulmond for their interesting comments on an earlier French version. This study has benefited from a grant from the ECCHIS network (Biologie des Ecosystèmes Chimiosynthétiques Profonds) for C.D.'s stay and travel to both the Roscoff and Strasbourg laboratories. During this work, C.D. was awarded a grant from IFREMER for her $\mathrm{PhD}$, defended at the Université de Bretagne Occidentale on December 6, 2011. We also wish to thank the referees for their constructive remarks, which greatly improved the manuscript.

\section{Literature Cited}

Ackers G.K. 1980. Energetics of sub-unit assembly and ligand binding in human hemoglobin. Biophys J 32:331-343.

Arp A.J., J.J. Childress, and C.R. Fisher. 1984. Metabolic and blood gas transport characteristics of the hydrothermal vent bivalve Calyptogena magnifica. Physiol Zool 57:648662.

Audzijonyte A., E.M. Krylova, H. Sahling, and R.C. Vrijenhoek. 2012. Molecular taxonomy reveals broad trans-oceanic distributions and high species diversity of deep-sea clams (Bivalvia: Vesicomyidae: Pliocardiinae) in chemosynthetic environments. Syst Biodivers 10:403-415.

Barry J.P. and R.E. Kochevar. 1998. A tale of two clams: differing chemosynthetic life styles among vesicomyids in Monterey Bay cold seeps. Cah Biol Mar 39:329-331.

Barry J.P., R.E. Kochevar, and C.H. Baxter. 1997. The influence of pore-water chemistry and physiology in the distribution of vesicomyid clams at cold seeps in Monterey Bay: implications for patterns of chemosynthetic community organization. Limnol Oceanogr 42:318-328.

Bradford M.M. 1976. A rapid and sensitive method for the quantitation of microgram quantities of protein utilizing the principle of protein-dye binding. Anal Biochem 72:248-254.

Bruneaux M., M. Rousselot, E. Leize, F.H. Lallier, and F. Zal. 2008. The structural analysis of large noncovalent oxygen binding proteins by MALLS and ESI-MS: a review on annelid hexagonal bilayer hemoglobin and crustacean hemocyanin. Curr Protein Pept Sci 9:150-180.
Bugge J. and R.E. Weber. 1999. Oxygen binding and its allosteric control in hemoglobin of the pulmonate snail, Biomphalaria glabrata. Am J Physiol 276:R347-R356.

Carney S.L., J.F. Flores, K.M. Orobona, D.A. Butterfield, C.R. Fisher, and S.W. Schaeffer. 2007. Environmental differences in hemoglobin gene expression in the hydrothermal vent tubeworm, Ridgeia piscesae. Comp Biochem Physiol B 146: 326-337.

Cavanaugh C.M. 1983. Symbiotic chemoautotrophic bacteria in marine invertebrates from sulphide-rich habitats. Nature 302:58-61.

Chiancone E., R. Elber, W.E. Royer, R. Regan, and Q.H. Gibson. 1993. Ligand binding and conformation change in the dimeric hemoglobin of the clam Scapharca inaequivalvis. J Biol Chem 268:5711-5718.

Childress J.J., C.R. Fisher, J.A. Favuzzi, A.J. Arp, and D.R. Oros. 1993. The role of a zinc-based, serum-borne sulphidebinding component in the uptake and transport of dissolved sulphide by the chemoautotrophic symbiont-containing clam Calyptogena elongata. J Exp Biol 179:131-158.

Childress J.J., C.R. Fisher, J.A. Favuzzi, and N.K. Sanders. 1991. Sulfide and carbon dioxide uptake by the hydrothermal vent clam, Calyptogena magnifica and its chemoautotrophic symbionts. Physiol Zool 64:1444-1470.

Cosel R.v. and K. Olu. 2009. Large Vesicomyidae (Mollusca: Bivalvia) from cold seeps in the Gulf of Guinea off the coasts of Gabon, Congo and northern Angola. Deep-Sea Res II 56:2350-2379.

Cosel R.v. and K. Olu-Le Roy. 2008. A new genus and new species of Vesicomyidae (Mollusca, Bivalvia) from cold seeps on the Barbados accretionary prism, with comments on other species. Zoosystema 30:929-944.

Decker C., J.C. Caprais, A. Khripounoff, and K. Olu. $2012 a$. First respiration estimates of cold-seep vesicomyid bivalves from in situ total oxygen uptake measurements. C R Biol 335:261-270.

Decker C., K. Olu, S. Arnaud-Haond, and S. Duperron. 2013. Physical proximity may promote lateral acquisition of bacterial symbionts in vesicomyid clam PlosONE 8:e64830. doi:64810.61371/journal.pone.0064830.

Decker C., K. Olu, R.L. Cunha, and S. Arnaud-Haond. $2012 b$. Phylogeny and diversification patterns among vesicomyid bivalves. PLoS ONE 7:1-8.

Fiala-Médioni A. and M. Le Pennec. 1987. Trophic structural adaptation in relation to the bacterial association of bivalve molluscs from hydrothermal vents and subduction zones. Symbiosis 4:63-74.

Fischer D., H. Sahling, K. Nöthen, G. Bohrmann, M. Zabel, and S. Kasten. 2012. Interaction between hydrocarbon seepage, chemosynthetic communities, and bottom water redox at cold seeps of the Makran accretionary prism: insights from habitat-specific pore water sampling and modeling. Biogeosciences 9:2013-2031.

Fisher C.R., J.J. Childress, A.J. Arp, J.M. Brooks, D.L. Distel, J.A. Dugan, H. Felbeck, et al. 1988. Variation in the hy- 
drothermal vent clam, Calyptogena magnifica, at the Rose Garden vent on the Galapagos site center. Deep-Sea Res 35: 1811-1831.

Goffredi S.K. and J.P. Barry. 2002. Species-specific variation in sulfide physiology between closely related vesicomyid clams. Mar Ecol Prog Ser 225:227-238.

Hashimoto J., S. Ohta, T. Tanaka, H. Hotta, S. Matsuzawa, and H. Sakai. 1989. Deep-sea communities dominated by the giant clam, Calyptogena soyoae, along the slope foot of Hatsushima Island, Sagami Bay, central Japan. Palaeogeogr Palaeoclimatol Palaeoecol 71:179-192.

Helms J. and U. Munzel. 2008. Nonparametric multiple comparisons. CRAN. http://cran.r-project.org/web/packages /npmc/.

Hourdez S., J. Lamontagne, P. Peterson, R.E. Weber, and C.R. Fisher. 2000. Hemoglobin from a deep-sea hydrothermalvent copepod. Biol Bull 199:95-99.

Kawano K., N. Iwasaki, and T. Suzuki. 2003. Notable diversity in hemoglobin expression patterns among species of the deepsea clam, Calyptogena. Cell Mol Life Sci 60:1952-1956.

Kraus D. 1990. Hemoglobins of the Lucina pectinata/bacteria symbiosis. II. An electron paramagnetic resonance and optical spectral study of the ferric proteins. J Biol Chem 265: 16054-16059.

Kraus D., J. Doeller, and C. Powell. 1996. Sulfide may directly modify cytoplasmic hemoglobin deoxygenation in Solemya reidi gills. J Exp Biol 199:1343-1352.

Kraus D.W. and J.B. Wittenberg. 1990. Hemoglobins of the Lucina pectinata/bacteria symbiosis. I. Molecular properties, kinetics and equilibria of reactions with ligands. J Biol Chem 265:16043-16053.

Krylova E.M. and H. Sahling. 2010. Vesicomyidae (Bivalvia): current taxonomy and distribution. PLoS ONE 5:1-9.

Levin L.A., W. Ziebis, G.F. Mendoza, V.A. Growney, M.D. Tryon, C. Mahn, J.M. Gieskes, and A.E. Rathburn. 2003. Spatial heterogeneity of macrofauna at northern California methane seeps: influence of sulfide concentration and fluid flow. Mar Ecol Prog Ser 265:123-139.

Nagel R.L. 1985. Molluscan hemoglobins. Pp. 227-247 in W.D. Cohen, ed. Blood cells of marine invertebates: experimental systems in cell biology and comparative physiology. Liss, New York.

Olu-Le Roy K., J.C. Caprais, A. Fifis, M.C. Fabri, J. Galéron, H. Budzinski, K. Le Ménach, A. Khripounoff, H. Ondréas, and M. Sibuet. 2007. Cold seep assemblages on a giant pockmark off West Africa: spatial patterns and environmental control. Mar Ecol 28:115-130.

Ondréas H., K. Olu, Y. Fouquet, J.L. Charlou, A. Gay, B. Dennielou, P. Donval, et al. 2005. ROV study of a giant pockmark on the Gabon continental margin. Geol Mar Lett 25:281-292.

Pop Ristova P., F. Wenzhöfer, A. Ramette, M. Zabel, D. Fischer, S. Kasten, and A. Boetius. 2012. Bacterial diversity and biogeochemistry of different chemosynthetic habitats of the REGAB cold seep (West African margin, $3160 \mathrm{~m}$ water depth). Biogeosciences 9:5031-5048.

Powell M.A. and A.J. Arp. 1989. Hydrogen sulfide oxidation by abundant nonhemoglobin heme compounds in marine invertebrates from sulfide-rich habitats. J Exp Zool 249: 121-132.

R Development Core Team. 2010. R: a language and environment for statistical computing. R Foundation for Statistical Computing, Vienna.

Sahling H., D. Rickert, R.W. Lee, P. Linke, and E. Suess. 2002. Macrofaunal community structure and sulfide flux at gas hydrate deposits from the Cascadia convergent margin, NE Pacific. Mar Ecol Prog Ser 231:121-138.

Scott K.M. and C.R. Fisher. 1995. Physiological ecology of sulfide metabolism in hydrothermal vent and cold seep vesicomyid clams and vestimentiferan tube worms. Am Zool 35:102-111.

Sibuet M. and K. Olu. 1998. Biogeography, biodiversity and fluid dependence of deep-sea cold-seep communities at active and passive margins. Deep-Sea Res II 45:517-567.

Sick H. and K. Gersonde. 1969. Method for continuous registration of $\mathrm{O}_{2}$ binding curves by means of a diffusion chamber. Anal Biochem 32:362-376.

Suzuki T., H. Kawamichi, R. Ohtsuki, M. Iwai, and K. Fujikura. 2000. Isolation and cDNA-derived amino acid sequences of hemoglobin and myoglobin from the deep-sea clam $\mathrm{Ca}$ lyptogena kaikoi. Biochim Biophys Acta 1478:152-158.

Suzuki T. and S. Ohta. 2000. The hemoglobin gene of the deep-sea clam Calyptogena soyoae has a novel intron in Ahelix. Int J Biochem Cell Biol 32:1205-1211.

Suzuki T., T. Takagi, and S. Ohta. 1989a. Amino acid sequence of the dimeric hemoglobin (Hb I) from the deep-sea coldseep clam Calyptogena soyoae and the phylogenetic relationship with other molluscan globins. Biochim Biophys Acta 999:254-259.

. 1989b. Primary structure of a dimeric haemoglobin from the deep-sea cold-seep clam Calyptogena soyoae. Biochem J 260:177-182.

Terwilliger R.C. and N.B. Terwilliger. 1985. Molluscan hemoglobins. Comp Biochem Physiol 81:255-261.

Terwilliger R.C., N.B. Terwilliger, and A. Arp. 1983. Thermal vent clam (Calyptogena magnifica) hemoglobin. Science 219:981-983.

Weber R.E. and S.N. Vinogradov. 2001. Nonvertebrate hemoglobins: functions and molecular adaptations. Physiol Rev 81:569-628.

Wittenberg J.B. 1970. Myoglobin-facilitated oxygen diffusion: role of myoglobin in oxygen entry into muscle. Physiol Rev 50:560-601.

Zal F., E. Leize, D.R. Oros, S. Hourdez, A.V. Dorsselaer, and J.J. Childree. 2000. Haemoglobin structure and biochemical characteristics of the sulphide-binding component from the deep-sea clam Calyptogena magnifica. Cah Biol Mar 41: 413-423. 